\title{
VARIACIÓN SINTÁCTICA EN EL ESPAÑOL EUROPEO: ENTRE NORMATIVA Y PROBLEMAS DESCRIPTIVOS Y EXPLICATIVOS
}

Carlos Felipe Pinto

\begin{abstract}
RESUMEN
Este trabajo discute algunos problemas de la variación sintáctica del español europeo observando las construcciones de escisión. A partir de datos obtenidos en estudios previos, mostramos que las verdaderas hendidas forman parte del vernáculo español (por lo menos en algunas variedades) y sugerimos que la fuerza normativa puede ser la causa de la "represión" de tales construcciones en la norma culta.
\end{abstract}

PALABRAS CLAVE: Sintaxis generativa; Escisión; Norma lingüística.

\section{Introducción}

partir de fines del siglo XIX, la variación del español comenzó a ser discutida de manera científica considerando las diferencias entre España 1 y América. Una conclusión muy importante a que se llega es la de que España y América no son dos bloques lingüísticos homogéneos y opuestos entre sí ${ }^{1}$. El español de América es el conjunto de variedades del español habladas en América, definidas histórica y geográficamente a partir del proceso de colonización y expansión españolas. En relación con el español europeo, Moreno Fernández ${ }^{2}$

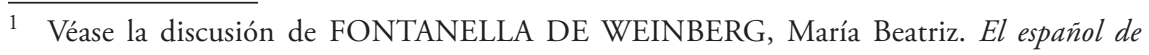
América. 2. ed. Madrid: Mapfre.1993.

2 MORENO FERNÁNDEZ, Francisco. Qué español enseñar. Madrid: Arco/Libros, 2000. 
sintetiza tres macrorregiones: la canaria, la andaluza y la castellana. Es cierto que se hace necesaria una división más minuciosa principalmente si se consideran los contactos lingüísticos observados en España, lo que hace que las distintas zonas dialectales tengan características propias distintas a las del centro de España.

Aunque se discuta la diversidad de la lengua española desde hace algún tiempo, una somera mirada hacia el tema deja claro que la sintaxis fue un aspecto muy poco discutido. Se puede observar una gran desproporción en muchos materiales entre la extensión de los capítulos de fonética/fonología y léxico y los capítulos de sintaxis (que, muchas veces, se restringen más bien a la morfología que a la sintaxis de hecho). Tal situación se debe a lo que señala Fernández Ordóñez ${ }^{3}$ : la sintaxis, tal como entendida actualmente, sólo gana terreno a partir de la década de 1950, con el surgimiento de la teoría de la gramática generativa. Hasta este entonces, los niveles de análisis principales y sobre los que se levantaron las teorías de historia y variación del español eran los niveles fónico y léxico.

Pinto $^{4}$ hace una amplia discusión sobre los criterios sintácticos en la división dialectal del español y muestra que los principales estudios de la variación lingüística del español estuvieron restringidos a las variedades cultas, tal como deja claro Lope Blanch5, planteando la pregunta de si las descripciones que hay sobre las diferentes variedades del español están basadas efectivamente en la lengua vernácula o en la norma culta. Es obvio que las distintas elecciones de objeto de investigación (la norma vernácula o la norma culta) pueden ofrecer resultados muy diferentes a las preguntas que se plantean ${ }^{6}$.

3 FERNÁNDEZ ORDÓÑEZ, Inés. "La variación gramatical en el español actual: estado de la cuestión y nuevas perspectivas”. In: V CONGRESSO BRASILEIRO DE HISPANISTAS/ I CONGRESSO INTERNACIONAL DA ABH. Belo Horizonte: UFMG, 2008.

4 PINTO, Carlos Felipe. Los criterios sintácticos en la división dialectal del español. In.: PINTO, Carlos Felipe; IRALA, Valesca Brasil (eds.). Um dossiê de estudos linguisticos hispânicos. São Paulo: Casa do Novo Autor, 2009. p. 61-97.

5 LOPE BLANCH, Juan Miguel. "La norma lingüística hispánica”. Anuario de Letras, 40, p. 23-41, 2002.

6 Lope Blanch, op. cit., llega a decir que es posible encontrar casos en que hay menos diferencias entre dos normas cultas de países diferentes que entre las normas culta y popular de un mismo país. Tal ponderación deja muy claro que lo que se está hablando en el mundo hispánico puede ser muy diferente de lo que se está registrando en obras descriptivas y, principalmente, normativas. 
Este trabajo tiene la finalidad de presentar evidencias de que hay un desajuste entre lo que se dice en los trabajos descriptivos basados en la intuición (y la normativa) y lo que se registra en los trabajos basados en datos de corpus, especialmente los corpus de lengua hablada en contexto de interacción real, considerando los aspectos sintácticos, que, como fue mencionado, son poco considerados en los estudios de la variación dialectal y social del español ${ }^{7}$.

\section{El objeto de estudio}

Los estudios sobre la escisión muestran que el español europeo presenta menos tipos de construcciones de escisión que otras lenguas, como el portugués y el inglés, y menos tipos que otras variedades del propio español, como el español caribeño ${ }^{8}$. Las construcciones de escisión ilustradas en (1), llamadas pseudohendidas, están presentes en todas las variedades del español, mientras que las construcciones de escisión ilustradas en (2), llamadas (verdaderas) hendidas, forman parte exclusivamente del espańol americano. Las construcciones ilustradas en (3) tienen particularidades?.

7 En este trabajo, discutiré la escisión pero la ponencia de Inés Fernández Ordóñez, en el V Congreso Brasileño de Hispanistas/I Congreso Internacional de la $\mathrm{ABH}$, deja claro que esta necesidad se aplica a otros aspectos de la sintaxis; por ejemplo, la autora muestra que el licenciamiento de objetos nulos en el español del País Vasco es distinto al de otras variedades españolas.

8 SORNICOLA, Rosanna. "It-clefts and wh-clefts: two awkward sentence types". Journal of Linguistics, 24: p. 348-79, 1988. PORTO DAPENA, José Álvaro. Oraciones de relativo. Madrid: Arco/Libros, 1997.

PINTO, Carlos Felipe. Uma análise das construçōes de clivagem e outras construçôes focalizadoras no espanhol atual. Dissertação de Mestrado, Universidade Federal da Bahia, 2008. BRITO, Ana Maria; DUARTE, Inês. Oraçóes relativas e construçóes aparentadas. En: MATEUS, M. H. M. et al. (eds.). Gramática da Lingua Portuguesa. Lisboa: Caminho, 2003. p. 653-694. MORENO CABRERA, Juan Carlos. Las funciones informativas: las perífrasis de relativo y otras construcciones perifrásticas. En: BOSQUE, Ignacio; DEMONTE, Violeta (eds.). Gramática descriptiva de la lengua española. 3. Madrid, Espasa Calpe, 1999. p. 4245-4302. DI TULLIO, Ángela. Clefting in spoken discourse. En: BROWN, K. (ed.). Encyclopaedia of Language and Linguistics, Cambridge, Elsevier Press, 2005. p. 483-491. DI TULLIO, Ángela. Hendidas, inferenciales y presentativas. En: DÉNIZ, Magnólia Troya; SAMPER PADILLA, José Antonio (eds.). Actas del XI Congreso Internacional de la Asociación de Lingüistica y Filología de la América Latina. v. 1. Las Palmas de la Gran Canária, 1999. p. 511-520.

9 Los ejemplos (1)-(3) se construyeron "artificialmente" con el mismo constituyente focalizado, un sintagma preposicionado, con el fin de dejar más evidente la tipología de la escisión. 
(1) a. De quien todos hablan es DE MARÍA

b. DE MARÍA es de quien todos hablan.

c. Es DE MARÍA de quien todos hablan.

(2) a. Es DE MARÍA que todos hablan.

b. DE MARÍA es que todos hablan.

(3) a. DE MARÍA que todos hablan.

b. Todos hablan es DE MARÍA.
Pseudohendida básica

Pseudohendida invertida

Pseudohendida extrapuesta

Hendida invertida

Hendida sin cópula

Pseudohendida reducida ${ }^{10}$

En este trabajo, presentaré algunos datos de las construcciones de escisión con la finalidad de corroborar la idea de Fernández Ordóñez de que la descripción de la (variación en la) sintaxis del espańol europeo necesita una revisión y que es imprescindible la inclusión de datos de lengua hablada en esa discusión. Los datos que más abajo se presentarán tienen un carácter introductorio y requieren, efectivamente, una ampliación para que las cuestiones planteadas aquí se comprueben.

A continuación, presentaré la definición de escisión que asumo en este trabajo y algunas características de esas construcciones que son relevantes para la discusión de los datos. Enseguida, presentaré los datos de la escisión (me detendré exclusivamente a las verdaderas hendidas ya que las pseudohendidas es-

10 Construcciones como la ilustrada en (3a) fueron registradas por Pinto op. cit. en el español europeo. Construcciones como la ilustrada en (3b) fueron registradas en datos del español caribeño por TORIBIO, Almeida Jacqueline (2002). Focus on clefts in Dominican Spanish. En: LEE, J; GEESLIN, K.; CLEMENTS, J. C. (eds.). Structure, Meaning, and Acquisition in Spanish. Somerville, Cascadilla Press, p. 130-146 y SEDANO, Mercedes. "Seudohendidas y oraciones con verbo ser focalizador em dos corpus del español hablado de Caracas”, Estudios de lingüistica del español, 23: s/p, 2006. Aunque construcciones como (3b) se encuentren en el espańol caribeño, hay variación en relación con la posibilidad de focalización del sujeto. KATO, Mary. Clivadas sem operador no português brasileiro. Comunicación presentada en el II Seminário do Projeto Temático da Fapesp "Sintaxe gerativa do português brasileiro na entrada do século XXI: minimalismo e interfaces”. São Paulo, Universidade de São Paulo, 2008 muestra que el punto central es la posibilidad de inversión V-S: variedades que exhiben el orden V-S también exhiben construcciones como (3b) para focalización del sujeto; variedades que no exhiben la inversión V-S tampoco exhiben construcciones como (3b) para focalizar el sujeto. 
tán bien descritas y efectivamente existen en todas las variedades del español ${ }^{11}$ ) desde varias perspectivas (cambio lingüístico, adquisición del lenguaje y variación lingüística, en este orden respectivamente ${ }^{12}$ y haré una discusión empírica de los datos.

\section{Referencial teórico}

Antes de pasar a la discusión empírica de la descripción y variación de la escisión, es importante ubicar al lector en las concepciones teóricas que tomo como punto de partida y qué fenómenos interesa averiguar. El análisis de la escisión tiene como soporte la teoría de Principios y Parámetros de la gramática generativa y los desarrollos posteriores del Programa Minimalista ${ }^{13}$. En este sentido, variedades de una misma lengua tienen el mismo estatuto que lenguas diferentes en relación con la concepción de parámetros ${ }^{14}$, lo que permite que se haga un análisis formal de la variación intralingüística ${ }^{15}$.

11 En el análisis de Pinto, op. cit., se muestra que, en tres de las cuatro variedades estudiadas (Argentina, Cuba, España y México), las pseudohendidas básicas representan más del $50 \%$ de los datos de escisión. En el caso del español europeo, representan el 63,1\% de los datos, que, sumado a los datos de pseudohendidas invertidas (7,9\%), significan más del 70\% de los datos.

12 Los datos de cambio y adquisición son tomados de investigaciones anteriores basadas en análisis de corpus. En PINTO, Carlos Felipe. Ordem de palavras, movimento do verbo e efeito V2 na história do espanhol. Tese de Doutorado, Universidade Estadual de Campinas, 2011, se analizaron textos diacrónicos del CORDE-RAE y en PINTO, Carlos Felipe. "La adquisición de la escisión en el español peninsular", Gragoatá, 30, p.168-188, 2011, se analizaron transcripciones de grabaciones de niños en el corpus CHILDES. Los datos que son efectivamente nuevos en este trabajo son los datos de variación, que se escucharon en charlas conmigo mismo y entre otras personas durante una estancia de investigación en Barcelona y los presenté en el XVI Congreso Internacional de la ALFAL, en 2011, en la ciudad de Alcalá de Henares.

13 CHOMSKY, Noam. El programa minimalista. Trad. Juan Romero Morales. Madrid: Alianza, 1995. CHOMSKY, Noam. Knowledge of Language: Its nature, origin and use. New York: Praeger, 1986.

14 Véase TORIBIO, Almeida Jacqueline. "Setting parametric limits on dialectal variation in Spanish”, Lingua, 10: 315-341, 2000.

15 La distinción propuesta por CHOMSKY, Noam. Knowledge of Language: Its nature, origin and use Op. cit. entre lengua-I (interna) y lengua-E (externa) es muy útil en este sentido. La lengua-I es la representación mental, individual de cada hablante. La lengua-E es el producto superficial y social. Como ejemplo, se puede citar el orden sujeto-verbo: el orden superficial S-V recibe representaciones diferentes en lenguas V2 y en lenguas no V2. Otro ejemplo es la discusión de Kato op. cit. sobre las pseudohendidas en el español del Caribe. 
En primer lugar, la definición de escisión que asumo es semejante a la que Modesto ${ }^{16}$ propone: "las construcciones hendidas son oraciones especificativas en que un movimiento A-Barra dispara lecturas características de contraste, exclusividad y exhaustividad" (traducción mía) ${ }^{17}$.

De esta manera, una oración como la ilustrada en (4) tiene dos lecturas posibles, que son ilustradas en $(5 \mathrm{a})$ y $(5 \mathrm{~b})$ :

(4) La que ha venido ha sido mi mujer. ${ }^{18}$

(5) a. Lectura especificativa:

Contexto: ¿Quién ha venido?

Vino mi mujer.

\section{b. Lectura atributiva:}

Contexto: ¿Quién es esa que ha venido?

La mujer que vino era mi mujer (pero ya no lo es).

De acuerdo con la definición adoptada, sólo construcciones con la lectura ilustrada en (5a) pueden considerarse construcciones de escisión teniendo en cuenta que el elemento escindido (el foco) tiene la función de establecer la referencia/valor de la variable que está abierta, representada por el pronombre relativo. Evidentemente, tal relación no se establece en (5b).

El segundo punto que merece la pena destacarse es la distinción estructural entre construcciones hendidas y construcciones pseudohendidas ${ }^{19}$. Las hendidas se constituyen realmente de dos oraciones, en que la oración principal nucleada por la cópula focalizadora domina la oración completiva (CP) que contiene la proposición real. Las pseudohendidas están constituidas por tan solo una oración copulativa en que la oración relativa libre ocupa la posición

16 MODESTO, Marcello. As construçôes clivadas no português do Brasil: relaçôes entre interpretação focal, movimento sintático e prosódia. São Paulo: Humanitas, 2001.

17 Una diferencia crucial entre el análisis que asumo y el de Modesto, op. cit., es que, en mi análisis, quien realiza el movimiento A-Barra es siempre el elemento focalizado. En el análisis de Modesto op. cit., hay un contraste: en las hendidas, el elemento focalizado realiza el movimiento A-Barra; en las pseudohendidas, quien lo realiza es la oración relativa libre.

18 Ejemplo tomado de Moreno Cabrera, op. cit., p. 4291.

19 Véase Modesto op. cit. 
de predicado y el elemento focalizado ocupa la posición de sujeto a semejanza de una oración pequeña (small clause $-S C)^{20}$.

El tercer aspecto, que es el punto central de mis investigaciones sobre la escisión, está relacionado con la alternancia "that"/"who" (que/quien) en construcciones de escisión del inglés (y sus equivalentes en las demás lenguas humanas). Las construcciones como las ilustradas en (6) son analizadas como teniendo la misma estructura por la tradición anglosajona:

(6) a. It was John that wore a white suit at the dance last night.

b. It was John who wore a white suit at the dance last night. ${ }^{21}$ "expl. era John quelquien llevaba un traje blanco en el baile anoche"

Modesto cuestiona la irrelevancia de esta alternancia a partir del contraste de los ejemplos en (6) con los datos en (7) a continuación:

(7) a. ${ }^{*}$ It was beautiful that wore a white suit last night.

b. It was beautiful who wore a white suit last night.

"expl. era guapo quelquien llevaba un traje blanco en el baile anoche"

Para este autor, si tal alternancia realmente fuera irrelevante, los datos en (7) también serían agramaticales, lo que es contrario a los hechos. Sin embargo, lo que Modesto deja de considerar en su análisis es que una de las características de la focalización es que el elemento focalizado es capaz de fijar el valor de una variable dejado en abierto como en una forma lógica ejemplificada en (8):

20 De todos modos, la estructura básica de la escisión puede ser representada como $\left[\mathrm{V}_{\text {ser }} \mathrm{CP} /\right.$ $\mathrm{SC}$, en la denotación generativa. En otra ocasión, un evaluador comentó que, si es así, no hay diferencia estructural. El lector debe tener en cuenta que la similitud es que, en ambos casos, el verbo copulativo focalizador selecciona un complemento. En el caso de la hendida, es una oración completa (CP); en el caso de la pseudohendida, es una oración pequeña (SC). Como el CP tiene una estructura distinta a la estructura de la SC, ambas construcciones efectivamente tienen estructuras diferentes, lo que es evidenciado através de algunos procesos sintácticos, como la concordancia, conforme señala Di Tullio, Ángela. Hendidas, inferenciales y presentativas, op. cit.

21 Ejemplos tomados de Modesto, op. cit., p. 19. 
(8) a. Existe un $x$ tal que $x$ está llorando.

b. $x=$ Pedro.

Sin embargo, como se observa en el contraste entre (9) y (10), las construcciones en (6) y (7) no son del mismo tipo:

(9) a. There is a $x$, such that $x$ wore a white suit at the dance last night. ${ }^{22}$

b. $x=$ John.

(10) a. There is a $x$, such that $x$ wore a white suit at the dance last night.

b. ${ }^{*} x=$ beautiful.

En (9), "John” fija el valor en abierto de la variable en la oración relativa. Por otro lado, "beautiful", en (10), no puede satisfacer el valor de esta variable, lo que muestra que las oraciones en (6) son oraciones especificativas y, por lo tanto, construcciones de escisión, mientras que las oraciones en (7) son oraciones atributivas y, como tal, no se caracterizan como construcciones de escisión y por eso la agramaticalidad de (7a)

Frente a estos hechos, mantengo el análisis de la tradición anglosajona, considerando las construcciones en (6) como estructuralmente idénticas, es decir, como verdaderas hendidas. La estructura que propongo para ambas construcciones es la misma; lo que las distingue es la variación en algún rasgo de concordancia entre la conjunción (el complementante) y el elemento focalizado en el sentido de la concordancia dinámica propuesta por Rizzi ${ }^{23}{ }^{24}$.

22 El significado de las fórmulas en (9) y (10) es semejante al de la fórmula en (8).

23 RIZZI, Luigi. "Residual verb second and the Wh criterion", Techinical Reports in Formal and Computational Linguistics, 2: s/p., 1991. Modesto, op. cit., propone un análisis distinto para las dos construcciones. En el caso de la pseudohendida extrapuesta, Modesto la analiza como una pseudohendida en el sentido de que hay una extraposición de la oración relativa para la derecha de la estructura. Tal análisis presenta problemas considerando dos puntos principales: a) los modelos generativos más recientes a partir de KAYNE, Richard. The Antisymmetry of Syntax. Cambridge: MIT Press, 1994, asumen que no hay movimiento de constituyentes a derecha; b) A partir de Chomsky, Noam. El programa minimalista op. cit., todo movimiento debe ser motivado y, en el análisis de Modesto op. cit., la extraposición de la oración relativa tiene la finalidad exclusiva de dar cuenta del orden lineal, lo que es totalmente inadecuado en el modelo teórico que adopta el propio Modesto, op. cit.. Así, se analizan la construcción en (1c) como hendida básica con concordancia y la construcción en (2a) como hendida básica sin concordancia.

24 Rizzi, op. cit., propone que hay dos tipos de concordancia entre núcleo y especificador: la 
Por fin, Zubizarreta ${ }^{25}$ propone que, en el español actual, están operantes reglas fonológicas que hacen que el elemento focalizado esté en la posición más baja en la estructura sintáctica para que pueda recibir el debido acento nuclear ${ }^{26}$. Esa regla fonológica explica por qué el español exhibe el orden verbo-sujeto obligatoriamente en respuestas a preguntas parciales cuando el foco es el sujeto:
(11) a. ¿Quién llegó?
b. Llegó Juan. / \#Juan llegó. ${ }^{27}$

Este hecho hace la previsión de que las únicas construcciones de escisión que se puede usar para el foco informativo son aquellas en que el foco es el elemento más bajo en la estructura, como la pseudohendida básica y la pseudohendida reducida. Tal previsión es confirmada por el contraste entre el español europeo y el portugués brasileño:

(12) a. ¿Quién llegó?

b. Quien llegó fue Juan. / \#Fue Juan quien llegó.

(13) a. Quem chegou?

b. Quem chegou foi o João. / Foi o João quem chegou. ${ }^{28}$

concordancia estática, en la que todos los elementos ya poseen sus rasgos equivalentes; la concordancia dinámica, en la que la concordancia ocurre cuando la relación de especificador-núcleo se establece. Es importante observar que la concordancia dinámica no puede infringir el Principio de la Proyección. Por ejemplo, un sintagma [-interrogativo] no puede convertirse en [+interrogativo] a lo largo de la derivación, lo que efectivamente no ocurre en este caso, ya que lo que está en juego son los rasgos formales y no los rasgos semánticos.

25 ZUBIZARRETA, Maria. Prosody, focus, and word order. Cambridge/Mass: The MIT Press, 1998.

26 Como bien destaca Zubizarreta, op. cit., esta regla sólo actúa en el caso del foco informativo, como representado en la fórmula en (8). En el caso del foco contrastivo, el respectivo acento nuclear puede incidir sobre cualquier posición en la oración sin que haya la necesidad de la alteración del orden.

27 La inversión es independiente del tipo del verbo. Ya sea inacusativo, inergativo o transitivo, tal inversión es obligatoria.

28 Brito y Duarte, op. cit., comentan que, en este mismo contexto, esta construcción no es posible en el portugués europeo. Es decir, sólo es posible en caso de foco contrastivo así como en el español europeo. 
A partir de este referencial teórico que presenté de manera muy reducida arriba, investigo la escisión: a) las construcciones de escisión son construcciones con estructura sintáctica y lectura semántica específicas; b) hay dos tipos (estructurales) de construcciones de escisión; c) el papel de la alternancia "who"/"that" (y sus equivalentes en diferentes lenguas); d) las construcciones de escisión tienen usos discursivos específicos ${ }^{29}$.

En el caso específico de esta investigación, me interesa discutir empíricamente aspectos relacionados con los puntos (b) y (c).

Es cierto que las hendidas forman parte diversas variedades del español americano aunque tienen una frecuencia baja y presentan restricción, en algunas variedades, en relación con el elemento focalizado como ya se ha señalado en diversos estudios ${ }^{30}$.

En los citados trabajos, se muestra que diversos constituyentes (incluyendo el sujeto) pueden focalizarse con construcciones hendidas (la básica y la invertida) y que, en el caso del espańol caribeño concretamente, se encuentran casos de hendidas básicas para la realización de un foco informativo, diferentemente de lo que pasa en el español europeo:

(14) Entrevistador: ¿Y hubo alguna Institución que te apoyaba en este tipo de....?

Entrevistado: Si, fue la Fundación Naumann, fundación Alemana que es la fundación que ayuda a los grupos liberales la que financió mi viaje. ${ }^{31}$

La variación que se encuentra en el Caribe insular está relacionada con la pérdida de la propiedad del sujeto nulo. Como a la propiedad del sujeto nulo

29 Véase, en este sentido, el estudio de PRINCE, Ellen. "A comparison of wh-clefts and it-clefts in discourse", Language, 54, p. 883-906, 1978 y PINTO, Carlos Felipe; RIBEIRO, Ilza. Um estudo sintático-discursivo comparativo da clivagem em línguas românicas. In: MOURA, Denilda (eds.). Os desafios da língua: estudos em língua falada e escrita. Maceió: EDUFAL, 2008. p. 401-404 en que hacen una breve comparación sintáctico-discursiva de la escisión en lenguas románicas a partir del original y traducciones del mismo texto y muestran que esas lenguas tienen distintos comportamientos en relación con el fenómeno de la escisión.

30 DI TULLIO, Angela. Clefting, in spoken discourse, op. cit., comenta que, aunque el español caribeño presenta las hendidas, no exhibe la focalización del objeto del verbo. Como se verá a continuación, en el español de Barcelona parece no existir tal restricción.

31 Ejemplo tomado de PINTO, Carlos Felipe. Uma análise das construçóes de clivagem e outras construçöes focalizadoras no espanhol atual, op. cit., p. 87. 
están asociadas otras propiedades (la inversión verbo-sujeto; el efecto that-trace etc.), cuando se pierde esta propiedad, las demás también se pierden. Por esa razón, en el español caribeño no se observan las restricciones fonológicas propuestas para las demás variedades del español. Como el español europeo, en todas sus variedades, sigue siendo una lengua de sujeto nulo, no se espera registrar tales efectos.

A continuación, comenzaré la discusión empírica de la escisión a partir de datos concretos obtenidos de corpus y registros de lengua hablada deteniéndome exclusivamente en los aspectos tipológicos de la escisión. Es decir, quiero discutir la variación (o más bien discrepancia) en la descripción y normativa del español europeo en relación con los diferentes tipos de construcción de escisión mostrando que los tipos que se dice no pertenecer a la variedad peninsular (aquellas construcciones ilustradas en (2)) sí forman parte de variedades vernáculas de esta región.

\section{Cuestiones de cambio lingüístico}

El primer grupo de datos que discutiré son los datos de cambio lingüístico. Moreno Cabrera comenta que, aunque las construcciones como las ilustradas en (2) no forman parte del estándar lingüístico europeo actual, fueron registradas en el Siglo de Oro en textos de Lope de Vega y Quevedo (siglo XVII), como se observa en los ejemplos en (15) a continuación:

(15) a. Es por celos de su amor que injustamente le afrenta.

b. Por vos es que yo he sufrido el oprobio $[\ldots]^{32}$

Discutiendo el efecto $\mathrm{V}^{33}$ en la historia del español, mostré que ya en

32 Ejemplos tomados de MORENO CABRERA. Op. cit., p. 4283.

33 El efecto de verbo segundo es una restricción en la que el verbo finito aparece en la segunda posición de la oración. La discusión sobre la relación de la escisión con el efecto de V2 comienza a partir de KATO, Mary; RIBEIRO, Ilza. Cleft sentences from Old Portuguese to Modern Portuguese. En: A. Duffer y D. Jakob (eds.). Focus and background in romance languages. London: John Benjamins, 2009. p. 123-154 y KATO, Mary; RIBEIRO, Ilza. A evolução das estruturas clivadas no português: período V2. En: LOBO, Tânia et alii (eds.). Para a história do português brasileiro. V. 2. Salvador: EDUFBA, 2006. p. 165-182, donde proponen que lenguas V2 no 
el español antiguo (siglos XII-XV) se encontraba la hendida básica como en el ejemplo (16a) y la hendida invertida, como en el ejemplo (16b):

(16) a. ...que ffuesse la mi merçed que mandasse entregar acada vno todo aquelles tomaron oles rrobaron olés quemaron, de aquellos quelo ffezieron. b. et d'esto es que se dize... ${ }^{34}$

A partir de la afirmación de Moreno Cabrera, se puede preguntar qué fue lo que cambió en la gramática (entendida en el sentido generativo, no tradicional ni normativo) del espańol para que las hendidas, como ilustrado en (2), (15) y (16), hayan desaparecido de la lengua.

Sin embargo, al analizar datos del español moderno (siglos XIX y XX), también encuentro ese tipo de construcción:

(17) a. es así que una de estas miserias fue sin duda el frío,

b. y fueron los hombres viciosos insectos que poblaron más tarde su oscura pelambrera.

c. así es que [...] acostumbraba retirarse tan pronto como se acababan las ceremonias, 35

Los datos en (16) y (17) muestran que, aparentemente, el español europeo no pasó por ningún cambio gramatical en relación con las construcciones de escisión desde los Siglos de Oro ya que las verdaderas hendidas se registran en el español antiguo, en el español de los Siglos de Oro y en el español moderno.

tienen las construcciones de escisión que empiezan con la cópula y comentan que, en la historia del portugués, esas construcciones solo aparecen cuando se pierde la propiedad V2. En este sentido, quise averiguar también tal condición en el español antiguo. Lo que se mostró fue que el español antiguo, aunque fuera una lengua V2 (con movimiento del verbo para CP), presentaba muchas oraciones V1. Como sólo se registra una construcción hendida básica (que se encuentra en una oración subordinada) y, paralelamente a este hecho, tampoco se registran oraciones copulativas matrices en que la cópula esté en primera posición, la hipótesis es la de que la restricción no se relaciona con la escisión en sí sino con el estatuto de la cópula misma. Sólo a fines del siglo XV se registran oraciones matrices encabezadas por la cópula.

${ }^{34}$ Ejemplos tomados de PINTO, Carlos Felipe. Ordem de palavras, movimento do verbo e efeito $V 2$ na história do espanhol. Op. cit., p. 114-115.

35 Ejemplos tomados de PINTO, op. cit., p. 136. 
Siguiendo la línea de pensamiento de Pagotto ${ }^{36}$, de que la norma culta también puede provocar innovaciones (al contrario de lo que se piensa siempre, que es la norma popular la que innova), se puede suponer que el español peninsular culto sufrió cambios lingüísticos mientras que la norma popular (que no está descrita adecuadamente) conserva características de tiempos pasados ${ }^{37}$.

El trecho a continuación presenta una evidencia para el hecho de que la norma culta/estándar puede estar actuando en la eliminación de tales construcciones ${ }^{38}$ :

La sanción que ha recaído sobre esta forma a partir de Bello ("crudo galicismo, con que se saborean algunos escritores sur-americanos", párrafo 812) desconoce su extensión panrománica, así como sus antecedentes estrictamente hispánicos. Lejos de toda intención de polemizar en el terreno de la normativa, podemos explicar su aparición y extensión, sin apelar al préstamo -retomando la interesante observación de Pedro Henríquez Ureña de que su uso no aparecer restringido a sectores que mantenían un contacto asiduo con el francés. ${ }^{39}$

A partir de ese fragmento, se puede imaginar que, ya en el siglo XIX, estas construcciones sonaban raras al estándar lingüístico europeo, lo que su-

36 PAGOTTO, Emílio. "Norma e condescendência; ciência e pureza". Lingua e Instrumentos Linguísticos, 2, p. 49-68, 1998, discute el cambio en la norma culta brasileña en el siglo XIX a partir del cambio por el que pasó el portugués europeo en este período. Sin embargo, se puede llevar la idea central de Pagotto, op. cit., a casos de otras lenguas, principalmente al caso del espańol, una lengua tan semejante y cercana geográficamente, con historia parecida y con centro legislador (la RAE) muy fuerte.

37 En este sentido, una posibilidad es la de que la variedad innovadora no sea el español caribeño, por ejemplo, pero el propio espańol europeo. Por otro lado, se puede suponer que las construcciones de escisión del español caribeño de hoy sean posibles por motivos diferentes de las construcciones del español europeo de los Siglos de Oro.

38 GROPPI, Mirta. "Estructuras con clíticos: revisión de terminología y datos del español". Signo \& Seña, 20, p. 93-113, 2009, encuentra construcciones de doblado de clíticos como "la vi a ella" en un corpus de lengua hablada en España. Y lo que comúnmente se viene diciendo es que dichas construcciones son exclusivas del espańol porteño.

39 DI TULLIO, Ángela. Hendidas, inferenciales y presentativas, op. cit., p. 6 (tomado del manuscrito). 
giere que el cambio en la normativa (o quizás en la norma culta) ocurrió entre los siglos XVII y XVIII.

\section{Cuestiones de adquisición}

A partir de la descripción que se tiene de la escisión en el español europeo, planteé la cuestión de si los niños españoles sólo estarían adquiriendo las construcciones pseudohendidas o si también habría hendidas en el habla de los niños ${ }^{40}$. En el caso de haber hendidas en la producción infantil, una cuestión que surge automáticamente es qué es lo que hace que los niños dejen de usar tal construcción: algún proceso natural de adquisición o factores externos, como la escolarización.

Para intentar echar luz a la cuestión, analicé datos de niños españoles entre 2 y 10 ańos de edad. A continuación, sintetizo la parte de los resultados que es relevante para esta discusión.

A los tres años, se registran tanto las hendidas básicas sin concordancia como las hendidas básicas con concordancia:

(18) a. es Tonti que está cantando...

b. es este el que lleva los guegalos... ${ }^{41}$

A los seis y a los ocho años se registran tanto casos de hendidas invertidas como las hendidas básicas con concordancia:

(19) a. él sí que se tiene que cortar el pelo... ${ }^{42}$

b. sería su padre el que repartía los premios...

c. yo es que ahora los veo muy poco... ${ }^{43}$

d. soy yo la que empiezo...

40 Véase la discusión completa en PINTO, Carlos Felipe. "La adquisición de la escisión en el espańol peninsular", op. cit., de donde se toman los datos de los ejemplos de (18) a (21).

41 guagalos" = "regalos".

42 Aunque a esta edad no se encuentran las hendidas invertidas del tipo "X es que", siguiendo el análisis de TORIBIO, Almeida Jacqueline (2002). Focus on clefts in Dominican Spanish. Op. cit. es posible analizar las construcciones con "X sí que" como construcciones del mismo tipo.

43 No se puede confundir esas construcciones con los casos en que la partícula "es que" introduce una oración presentativa como "es que no fui a la clase" precedida por un tópico discursivo "yo, es que no fui a la clase". DI TULLIO, op. cit., presenta una distinción entre esos tipos de construcción. El ejemplo (20a) es un claro caso de foco discursivo (en PINTO, op. cit., se presentan los contextos de los datos). 


\section{A los nueve y diez años, se encuentran ejemplos de hendidas invertidas:}

(20) a. la operación fue que me hicieron en el ojo...

b. tú sí que serías un buen padre...

c. yo es que por la noche el día de Reyes no puedo dormir...

Los datos mostraron que las construcciones pseudohendidas aparecen muy tempranamente y permanecen en todas las edades, excepto a los dos años. Sin embargo, es intrigante ver construcciones que, según diversos autores, no forman parte del español europeo adulto producidas por niños diferentes y de diversas edades.

Se registra tan solo un caso de hendida básica sin concordancia en un niño de tres años, quien produce también una hendida básica con concordancia, lo que puede indicar que el niño todavía no haya aprendido la concordancia de la escisión en el espańol europeo ${ }^{44}$.

Sin embargo, algo problemático para la descripción de la escisión en el español europeo es la alta productividad de hendidas invertidas en el habla de los niños. No parece aceptable que un niño no haya fijado los parámetros de su lengua a los diez años de edad. La única explicación viable, en este sentido, es que la norma culta/estándar (representada por la escuela) es lo que está eliminando estas construcciones del habla de las personas. Una evidencia para este hecho es el contraste entre los datos entre dos trabajos que realicé anteriormente: en un primer momento, analicé material escrito (entrevistas y guiones de películas) y no registré ningún caso de hendida invertida en el español europeo. Posteriormente, cuando investigué la producción infantil en contexto de interacción espontánea con los adultos, registré diversos casos de hendidas invertidas en el habla de diferentes adultos:

(21) a. tú es que lo haces en ochocientos años...

b. tú es que ya lo entiendes...

44 En el análisis que propongo, el español europeo tendría la estructura de la hendida básica. El problema es explicar qué elimina, por un lado, la variante default "que" y permite, por otro, las opciones marcadas. En los datos analizados en PINTO, Carlos Felipe. Uma análise das construçōes de clivagem e outras construçóes localizadoras no espanhol atual, op. cit., las hendidas con concordancia representan el $23,7 \%$ de los datos de escisión. Considerando que el $64,9 \%$ estaba representado por las pseudohendidas básicas, los datos de hendidas con concordancia no son irrelevantes ni indican poca productividad de este tipo de construcción. 
El contraste de los resultados puede ser el reflejo de un proceso más amplio, que es la escolarización y la tensión de la normativa: en los géneros/ contextos en que la normativa parece no intervenir (es decir, en la lengua hablada en interacción espontánea), se registran construcciones hendidas invertidas; en los géneros que reciben claros influjos de la normativa (el caso de las entrevistas y los guiones), tales construcciones no aparecen ${ }^{45}$.

\section{Cuestiones de variación}

El último conjunto de datos (los que son efectivamente nuevos en este trabajo) que discutiré está relacionado con la variación de la escisión dentro del español europeo mismo. La amplia bibliografía sobre la escisión en el español viene mostrando que el español no presenta uniformidad y el español caribeño es una de las variedades que presenta más tipos de construcciones (quizás, como ya he comentado, como consecuencia de la pérdida de una propiedad más profunda). Sin embargo, nada se dice de la variación interna del espańol europeo.

Los ejemplos en (22), producidos por distintos hablantes y en momentos diferentes, muestran que, en el español de Barcelona, las hendidas son posibles.

(22) a. Eso fue Andrea que lo rompió.

b. Fueron ellos, fueron ellos que me buscaron. ${ }^{46}$

45 Muy interesante en este sentido es el dato en (i):

Los niños pequeños es que son unos animales.

tomado de JØRGUENSEN, Annette Myre. Formas de tratamiento: los vocativos em el lenguaje juvenil de Madrid, Buenos Aires y Santiago de Chile. En: REBOLLO COUTO, Leticia; LOPES, Celia (eds.). As formas de tratamento em português e em espanhol: variação, mudança e formas conversacionais/Las formas de tratamiento en español y en portugués: variación, cambio y funciones conversacionales. Niterói: Editora da UFF, 2011. p. 125-148, donde la autora analiza los vocativos en diversos corpus de lengua hablada observando específicamente el lenguaje juvenil. Este dato es encontrado en el corpus de Madrid, lo que refuerza que hay un serio problema en la descripción del español europeo más allá de un problema de variación dialectal.

46 Los ejemplos (22a) y (22b) fueron producidos por el mismo hablante en momentos distintos, que es catalán y bilingüe castellano-catalán. Lo curioso es que, días antes de que produjera el primer ejemplo, lo consulté sobre la gramaticalidad de esta construcción y la respuesta fue tajante: “¡está mal dicho!”. Cuando produjo tal enunciado, le dije que me había dicho 
c. Es algo así que te digo yo.

d. Parece que tú seas serio y a partir del próximo mes es contigo que yo hablo. ${ }^{47}$

Quizás, la posibilidad de estas construcciones sea el resultado del contacto entre el español y el catalán ${ }^{48}$. Si esas construcciones son posibles por el contacto con el catalán no quita la legitimidad de una variedad dialectal específica distinta a la variedad del centro de España, por ejemplo. Como se discute extensamente en Tuten ${ }^{49}$ para el caso del contacto de lenguas en la formación del español medieval, cuando una koiné se convierte en la lengua materna de una generación, deja de ser una koiné y pasa a ser una variedad de la lengua. Así, como hay hablantes nativos (bilingües o no) de la variedad del español hablado en Cataluña, esta variedad lingüística recibe el mismo estatuto (por lo menos desde el punto de vista estrictamente lingüístico) que las demás variedades que no poseen contacto con otras lenguas en la actualidad.

\section{Conclusiones}

Este texto tuvo la finalidad de problematizar lo que se viene diciendo sobre la escisión en el español europeo actual a partir de tres perspectivas. La idea central fue intentar mostrar que no hubo un cambio en la historia del español y que hay una posible variación (diatópica y diafásica) provocada por una tensión normativa en la actualidad.

que estaba mal dicho y me contestó que una cosa es la gramática y otra cómo habla la gente, lo que refuerza, una vez más, mi hipótesis de la tensión normativa en la represión de esas construcciones.

47 Este ejemplo es el habla de un personaje de la película "Una casa de locos", que fue grabada en Barcelona. Aunque muchos de los personajes son estudiantes Erasmus, el personaje que dice este enunciado era el administrador (el señor que alquila) del piso, claramente catalán.

48 Algunos informantes dijeron que el catalán sólo tiene las hendidas sin concordancia. Sin embargo, escuché también la variante con concordancia. Esta discrepancia puede estar relacionada con la variación misma del catalán o con el influjo del español (castellano) en el catalán, ya que los contactos lingüísticos dejan huellas recíprocas en ambas lenguas.

49 TUTEN, Donald. Koineization in Medieval Spanish. Berlin/Nova Iorque: Mouton de Gruyter, 2003. 
Las construcciones llamadas pseudohendidas tienen mucha producción en todas las variedades del español. Las construcciones hendidas se registran en medida mucho menor y se suele decir que, en la actualidad, sólo forman parte de algunas variedades del español americano. Los diversos datos que presenté a lo largo del trabajo muestran que dicha asumpción no es cierta.

Desde el punto de vista del cambio lingüístico, mostré que, tanto en el español antiguo como en el español moderno, hay registro de construcciones hendidas, tanto la hendida básica como la hendida invertida. Aunque esas construcciones hayan sido utilizadas en ambientes formales y cultos en tiempos pasados, como en los textos de Lope de Vega y Quevedo, en el siglo XIX parece estar ya establecido un cambio en la norma culta y, debido a la tensión de la normativa, que reprime esas construcciones en el estándar peninsular quizás por un rechazo al supuesto galicismo, ya no forman parte del estándar lingüístico europeo ${ }^{50}$. Este hecho queda evidente cuando se observa la conciencia lingüística de los hablantes: cuando se les pregunta qué opción es gramatical (en el sentido de qué construcción se produce independientemente de su valor normativo) contestan siempre que es "Juan quien llegó", por ejemplo; pero como se pudo ver, en otras situaciones espontáneas, dicen la variante por defecto "que". El ejemplo que se registra en el estudio de Jørguensen, con el lenguaje juvenil parece mostrar lo mismo considerando que los jóvenes, especialmente en grupo, no están ligados a estándares normativos.

Desde el punto de vista de la adquisición del lenguaje, señalé que niños producen esas construcciones de escisión que suelen decir que no forman parte de la lengua adulta. Mostré que la hendida invertida también es producida por hablantes adultos que interactuaban con esos niños, lo que pone en evidencia una vez más, a partir de la comparación con los resultados del análisis

50 El cambio gramatical no actúa necesariamente en conjunto. Es posible encontrar cambios gramaticales aislados, principalmente si se trata de una cuestión normativa, conforme discute Pagotto op. cit.. En el caso del español, si pensamos en la colocación pronominal, se observa un cambio gramatical más profundo entre los siglos XV y XVI (la pérdida del efecto V2), conforme señala FONTANA, Josep María. Phrase structure and the Syntax of clitics in the history of Spanish. Tese (Doutorado em Lingüística), Universidade da Pensilvânia, 1993, pero el uso de la énclisis con verbos finitos se extiende en el español europeo hasta fines del siglo XIX (Véanse los datos de PINTO, Carlos Felipe. Ordem de palavras, movimento do verbo e efeito V2 na história do español, op. cit., p. 269-271). Sólo en el siglo XX se deja de usar completamente la énclisis con verbos finitos en el español. 
de los textos escritos, que la normativa es lo que realmente excluye tales construcciones ${ }^{51}$.

Del punto de vista de la variación lingüística, mostré que, en el español de Cataluña, específicamente en Barcelona, se encuentran ambos tipos de construcciones hendidas en contextos variados de habla espontánea en distintos hablantes.

Frente a esos datos, parece ser un hecho sin controversias que las pseudohendidas son más productivas en las variedades del español en general, lo que reduce bruscamente las posibilidades de otros tipos de construcciones de escisión en términos cuantitativos. Sin embargo, un estudio sociolingüístico más amplio basado en diversos géneros textuales y en datos de lengua hablada en interacción real puede aclarar de manera más satisfactoria cuál es la verdadera situación de las hendidas en el espańol europeo: si, efectivamente, no forman parte de la gramática de esta variedad (es decir, si lo que se registra es un

51 GÓMEZ TORREGO, Leonardo. Gramática didáctica del español. 8. ed. Madrid: Ediciones SM, 2002. ofrece una evidencia más al carácter normativo o culto del fenómeno (destaques míos):

En las estructuras u oraciones ecuacionales, cuando el componente que no es la oración de relativo lleva preposición, ésta debe mantenerse en el componente u oración de relativo, al menos según la norma culta del español de España. Ejemplo:

*Fue por Juan que me enteré de lo sucedido (se dice: fue por Juan por el que (quien) me enteré...).

Tampoco se consideran correctas las oraciones ecuacionales formadas con adverbios interrogativos y un relativo que. Sin embargo, son relativamente frecuentes en Hispanoamérica. Ejemplos:

${ }^{*}$ ¿Cuándo fue que viniste? (en España se dice: ¿¿cuándo viniste?)

* ¿Cómo fue que lo hiciste? (en España se dice: ¿cómo lo hiciste?)

Tampoco pertenecen a la norma culta del español de España las estructuras ecuacionales en que aparece un que en vez de un adverbio. Ejemplo:

*Ayer fue que vino (en Espańa se dice: ayer fue cuando vino).

Hay alguna contradicción entre los datos empíricos y lo que dice Gómez Torrego op. cit. También se registraron casos de adverbios (con la predominancia de "asî") en hendidas básicas sin concordancia y hendidas invertidas. En la primera presentación que hice de este trabajo en el XVI Congreso Internacional de la ALFAL, realizado en Alcalá de Henares en julio de 2011, una española que asistía a mi presentación comentó al final que este adverbio puede ubicarse libremente en las hendidas generando la variación libre (libre desde el punto de vista sintáctico, aunque pueda haber alguna especificidad discursiva) entre "así es que...” y "es así que...". 
problema de desempeño lingüístico); si hay variación social o estilística en el uso de esas construcciones; o si simplemente hay un problema de frecuencia. Por lo aquí expuesto, parece ser claro, sin embargo, que la primera opción es la menos probable haciendo suponer que el problema reside en las dos opciones que quedan: o hay un problema de variación social/estilística o de frecuencia.

Otras cuestiones, desde un punto de vista más teórico, también necesitan respuestas. Entre ellas: a) qué propiedades sintácticas y discursivas del español (excepto en el Caribe) están restringiendo/reteniendo la tipología de la escisión de modo que las pseudohendidas sean mucho más productivas; b) si la estructura de las hendidas existe (el español europeo tiene las hendidas con concordancia), por qué la hendida básica sin concordancia es tan poco productiva, casi inexistente ${ }^{52}$; c) cuál es la real naturaleza de la alternancia "who"/"that" en las construcciones de escisión en las lenguas humanas como un todo.

\title{
SYNTACTIC VARIATION IN EUROPEAN SPANISH: BETWEEN NORMATIVE AND DESCRIPTIVE AND EXPLANATORY PROBLEMS
}

\begin{abstract}
This paper discusses some problems of syntactic variation in European Spanish focusing on cleft sentences variation. From data obtained in previous studies, we show that the true clefts are present in vernacular European Spanish (at least in some varieties) and we suggest
\end{abstract}

52 En el análisis de Kato y Ribeiro, op. cit., las hendidas invertidas tienen la misma estructura que las hendidas básicas. La diferencia entre ellas está relacionada con el lugar de aterrizaje del elemento focalizado. En las hendidas básicas, el CP subordinado carga el rasgo [+foco] mientras que, en las hendidas invertidas, el CP subordinado carga el rasgo [-foco] obligando el elemento focalizado a moverse al CP matriz. Además, otro problema es explicar por qué no hay hendidas básicas y hay hendidas invertidas: Kato y Ribeiro, op. cit., muestran que las hendidas invertidas aparecen antes que las hendidas básicas en la historia del portugués. En PINTO, Carlos Felipe. Uma análise das construçôes de clivagem e outras construçōes localizadoras no espanhol atual, op. cit,. se muestra que, en el español cubano, hay más casos de hendidas invertidas que de hendidas básicas. 
that the normative force may be the cause of the "repression" of such constructions in the educated norm.

KEYWORDS: Generative Syntax; Cleft sentences; Linguistic norm.

Recebido em: 13/03/2013

Aprovado em: 12/08/2013 